\title{
A New Graphical Technique for Energy Efficient Design of Heat Recovery System in Chemical/Refining Industries
}

\author{
https://doi.org/10.3991/ijes.v4i4.6543 \\ Dina Kamel ${ }^{1}$, Mamdouh Gadalla ${ }^{1}$ and Fatma Ashour ${ }^{2}$ \\ ${ }^{1}$ British University in Egypt, Cairo, Egypt \\ ${ }^{2}$ Cairo University, Cairo, Egypt
}

\begin{abstract}
Chemical processes are energy intensive industries; the majority of energy consumed in industrial processes is mainly used for heating and cooling requirements. This results in increasing the interest in obtaining the optimum design of the heat exchanger networks to reduce the energy consumption and face the growing energy crises.

Most of the published literature over the last fifty years promotes the process integration technology as a main part of the process system engineering science. Graphical Pinch Analysis method normally includes two key steps, firstly obtaining the energy targets which include the minimum energy required for the HEN design, then designing the heat exchanger network (HEN).
\end{abstract}

This paper introduces a new graphical approach for the design of new heat exchanger networks (HENs) based on pinch analysis rules. The HEN is represented on a simple graph, where the cold stream temperatures are plotted on the $\mathrm{X}$-axis while the driving forces for each exchanger are plotted on the $\mathrm{Y}$-axis. This graphical technique can describe the energy analysis problems in term of temperature driving force inside the heat exchanger, which is an important factor in the design process as the differences in these driving forces are involved in calculating the area of heat exchangers, and consequently affecting the cost.

Index Terms-Heat exchanger network; Energy saving; Grassroots design; Pinch analysis; Heat integration

\section{INTRODUCTION}

The Renewable Academy of Germany [1], performed a statistical analysis to that highlighted that total heat energy consumption in the German industry is more than three times higher that of electrical energy consumption. Heat integration using pinch analysis was developed by Linnhoff and Hindmarsh [2], they proposed three essential strategies to decrease the energy requirements; firstly avoid the transfer of heat across the pinch, secondly avoid the presence of coolers above the pinch, and finally avoid the presence of heaters below the pinch. They emphasized that any error in following the mentioned guidelines increases the actual consumption of energy. The determination of the minimum energy targets were either done graphically by the composite curves e.g. by Smith [3], or numerically by problem table algorithm [4].

Smith [3] and Klemes [5] provided the complete steps for the design of the composite curves, and obtaining the maximum achieved energy for a given minimum tempera-

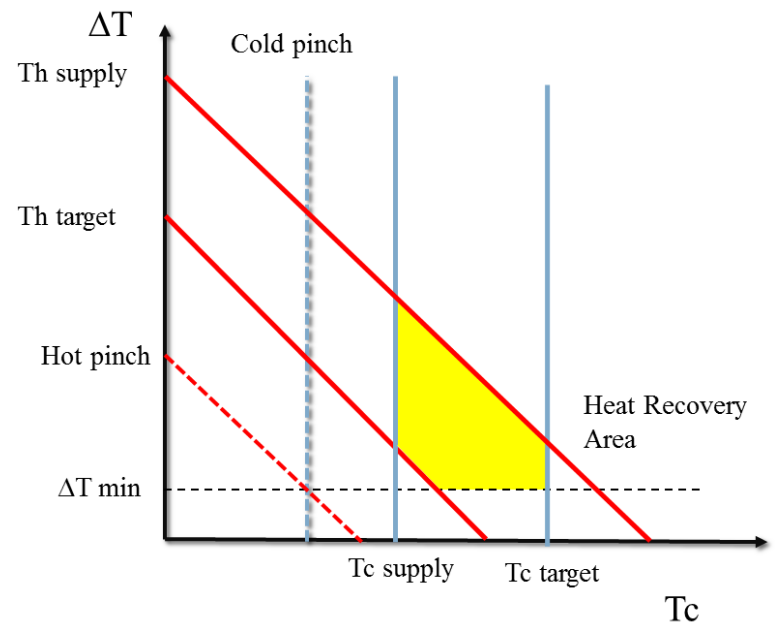

Figure 1. New graphical representation

ture difference $(\Delta \mathrm{T}$ min) for certain process, based on pinch analysis rules.

Graphical pinch analysis method normally includes two key steps, firstly obtaining the energy targets which include the minimum energy required for the HEN design, then designing the heat exchanger network (HEN). The design of heat exchanger network typically depends on pinch temperatures and minimum utility requirements [6].

\section{NEW TEMPERATURE - DRIVING FORCE (TDF) GRAPHICAL APPROACH}

The new graphical approach uses the basic principles of pinch analysis. Fig. 1 depicts an X-Y diagram for such a plot. In the new analysis, exchangers are represented as straight lines. The starting point is the hot end driving force, and the end point is the cold end driving force. The coordinates that identify each point on the graph are:

- The X-coordinate is the cold stream temperature at one end.

- The Y-coordinate is the driving force across that end.

The hot end driving force ( $\Delta$ The) is calculated by subtracting the target cold temperature (Tct) from the supply hot temperature (Ths), while the cold end driving force $(\Delta \mathrm{Tce})$ is calculated by subtracting the supply cold temperature (Tcs) from the target hot temperature (Tht). Characterizations of the new graphs are summarized below: 
1. The cold stream lines are represented as vertical lines starting at Tc on the $\mathrm{X}$-axis, while the hot stream lines are represented as inclined straight lines starting from $\Delta \mathrm{T}=\mathrm{Th}$ on the $\mathrm{Y}$-axis $(\mathrm{Tc}=\mathrm{zero}$ ) and ending at $\mathrm{Tc}=\mathrm{Th}$ on the $\mathrm{X}$-axis $(\Delta \mathrm{T}=$ zero $)$ as shown Fig.1., Fig.2 shows that locus of each point on the graph.

2. All hot streams are parallel to the hot pinch line, and, similarly, all cold streams are parallel to the cold pinch line.

3. Assuming constant heat capacities for process streams, each exchanger can be represented by a straight line drawn between (Tcs, $\Delta$ Tce) and (Tct, $\Delta$ The), as shown in Fig.3.

The slope of the exchanger is determined as the ratio between the difference in the driving force and the difference in the cold temperature for a certain stream as shown in Eq.1 which is involved in the heat transfer process.

$$
\mathrm{S}=\frac{\Delta \mathrm{T}_{\mathrm{he}}-\Delta \mathrm{T}_{\mathrm{ce}}}{\Delta \mathrm{T}_{\mathrm{c}}}
$$

By simplification of Eq.1, the slope is related to the ratio of heat capacity flow (CP) as seen from Eq.2.

$$
\mathrm{S}=\frac{\mathrm{CPc}}{\mathrm{CPh}}-1
$$

Applying the same procedure on the length of the heat exchanger, proposed that the length is directly proportional to the duty of the exchanger. The advantage of the new graph is that it divided the energy analysis into 5 regions according to the pinch analysis principals as shown in Fig.4: Region 1 and 3 are optimum regions for heat exchangers, while Region 2 and 5 are non-optimum regions for heat exchangers (i.e. crossing the pinch). On the other hand, Region 4 is below the $\Delta \mathrm{T}=$ Zero line so the presence of any heat exchanger in this region is infeasible.

\section{PROCEDURE FOR GRAPHICAL DESIGN}

1. Plot all process streams on the graph by using the given supply and target temperatures. Also, plot the hot pinch temperature line, the cold pinch temperature line and the $\Delta$ Tmin line. Fig. 5 represents graphically the process streams presented in Table 1 for two hot streams and two cold streams $(\mathrm{C} 1, \mathrm{C} 2, \mathrm{H} 1, \mathrm{H} 2)$. The highlighted regions in the figure are the optimum regions for heat integration above and below the pinch.

2. Divide the design of the network above and below the pinch.

3. The starting point for design above the pinch is the intersection between the hot target temperature line (Tht) and the cold supply temperature line (Tcs). If Tht is less than the hot pinch temperature (Thp), start at Thp instead of Tht. If the cold supply temperature (Tcs) is less than the cold pinch temperature (Tcp), start at Tcp.

4. Recover all the heat above the pinch by selecting the best matches. This should be where the hot streams will be cooled from their supply temperatures to the hot pinch temperature (Thp), if their target temperatures are below the pinch. If their target temperatures are above the pinch, they will be cooled to only their target temperatures.

5. The starting point for design below the pinch is the intersection between the hot supply temperature line (Ths) and the cold target temperature line (Tct). If Ths is above the hot pinch temperature line (Thp), start at Thp instead of Ths. If the cold target temperature (Tct) is above the cold pinch temperature line (Tcp), start at Tcp.

6. All cold streams will be heated from the cold pinch temperatures or their supply temperatures if they lie above the pinch. In this case, place a heater (hot utility) for the remaining cold streams to fulfill the heating required.

7. Merge the above parts to obtain a complete heat exchanger network

The above procedure is applied on the data presented in Table 1, the design of the HEN is represented in Fig.6, while the summery of the HEN is presented in Table II.

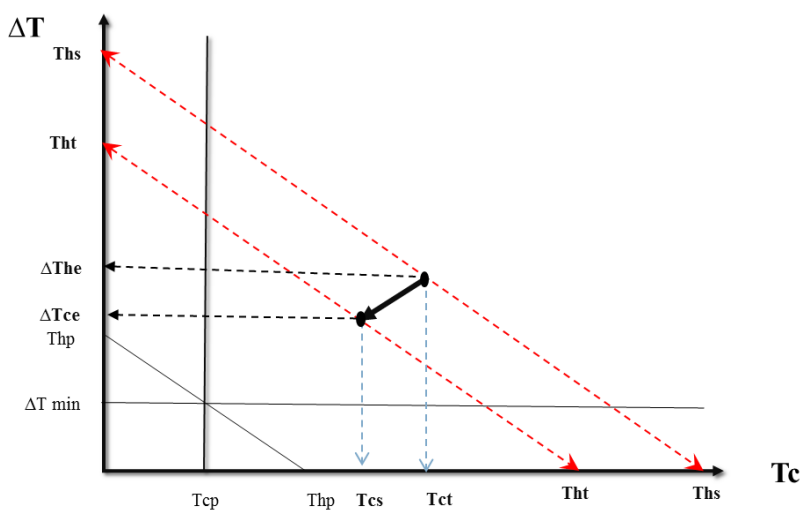

Figure 2. New graphical representation

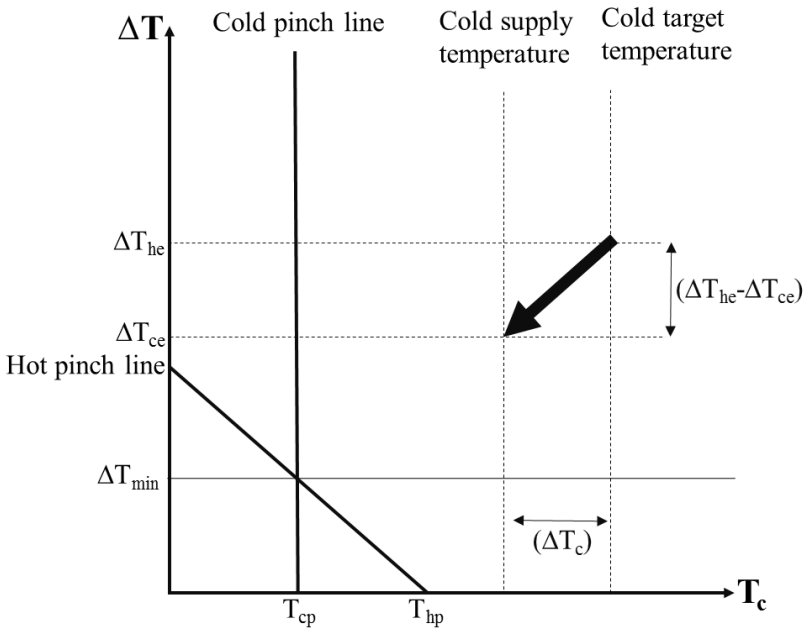

Figure 3. Locus of each point

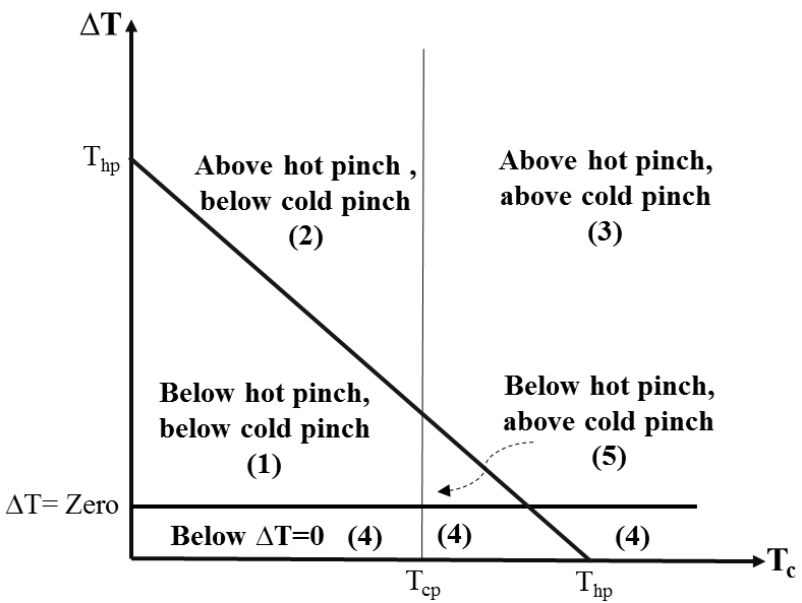

Figure 4. Locus of each point 
TABLE I.

STREAM DATA

\begin{tabular}{lcccc}
\hline Stream & Ts $\left({ }^{\mathbf{0}} \mathbf{C}\right)$ & $\mathbf{T t}\left({ }^{\mathbf{0}} \mathbf{C}\right)$ & Duty & $\mathbf{C P}\left(\mathbf{M W} /{ }^{\mathbf{0}} \mathbf{C}\right)$ \\
\hline $\mathrm{H} 1$ & 250 & 40 & 31.5 & 0.15 \\
$\mathrm{H} 2$ & 200 & 80 & 30 & 0.25 \\
$\mathrm{C} 1$ & 20 & 180 & -32 & 0.2 \\
$\mathrm{C} 2$ & 140 & 230 & -27 & 0.3 \\
\hline
\end{tabular}

TABLE II.

SUMMARY FOR THE HEN

\begin{tabular}{lccccc}
\hline $\begin{array}{c}\text { Heat exchang- } \\
\text { er }\end{array}$ & Tes $\left({ }^{\mathbf{0}} \mathbf{C}\right)$ & Tet $\left({ }^{\mathbf{0}} \mathbf{C}\right)$ & Ths $\left({ }^{\circ} \mathbf{C}\right)$ & Tht $\left({ }^{\circ} \mathbf{C}\right)$ & $\begin{array}{c}\text { Duty } \\
(\mathbf{M W})\end{array}$ \\
\hline $\mathrm{C} 1 / \mathrm{H} 1$ & 140 & 180 & 203.33 & 150 & 8 \\
$\mathrm{C} 2 / \mathrm{H} 2$ & 140 & 181.67 & 200 & 150 & 12.5 \\
$\mathrm{C} 2 / \mathrm{H} 1$ & 181.67 & 205 & 250 & 203.33 & 7 \\
$\mathrm{H}$ eater for $\mathrm{C} 2$ & 205 & 230 & 240 & 239 & 7.5 \\
$\mathrm{C} 1 / \mathrm{H} 2$ & 52.5 & 140 & 150 & 80 & 17.5 \\
$\mathrm{C} 1$ '/H1 & 20 & 52.5 & 150 & 106.67 & 6.5 \\
$\mathrm{Cooler}$ for H1 & 20 & 30 & 106.67 & 40 & 10 \\
\hline
\end{tabular}

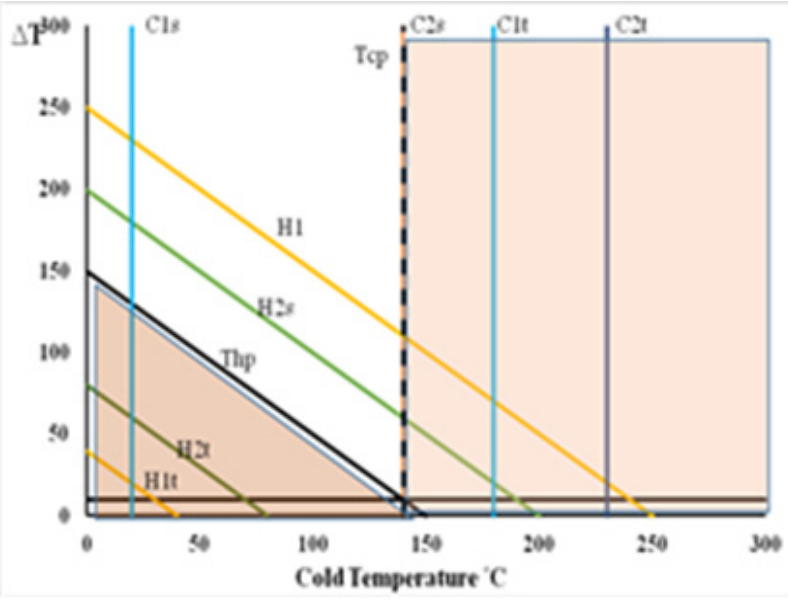

Figure 5. A plot for all process streams

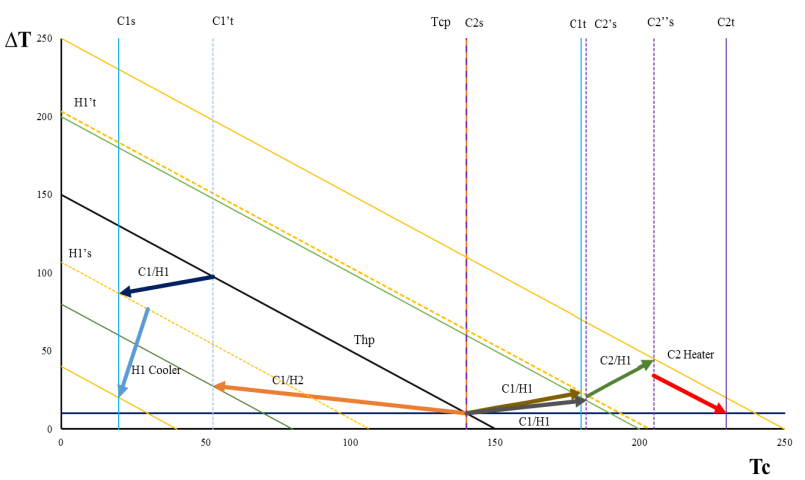

Figure 6. Final HEN

\section{CONCLUSION}

The new technique follows completely the pinch analysis rule, but its advantages is that is it simple as each exchanger can be represented by a straight line, visual and indicative as both the length of the line and its slope has important physical meanings, also the feasible regions for heat integration are easily identified visually more over easy and simple identification of possible optimum matches. With a systematic procedure, this graphs are employed to generate new designs of exchanger networks and also to modify existing ones for better performances. In addition to its simplicity and visual-interface, the new design methodology is characterized by several benefits, including:

- No need for complex or commercial simulation or software packages.

- Instantaneous determination of the value of the driving force for each exchanger to avoid the presence of network pinch.

- Good selection of accepted and excluded matches regarding the driving force.

- Visualization in design especially for low temperature applications.

\section{REFERENCES}

[1] Renwables Academy (RENAC), 2009, A Lecture for a Work Shop on Renewable Energy and Energy Efficiency, Berlin, Germany.

[2] Linnhoff, B. and Hindmarsh, E., 1983, The Pinch Design Method for Heat Exchanger Networks, Chemical Engineering Science, vol. 38, no. 5, p. 745-763. https://doi.org/10.1016/0009-2509(83) $\underline{80185-7}$

[3] Smith, R., 2005, Chemical Process Design and Integration, England: John Whiley \& Sons Ltd.

[4] Linnhoff, R., and Flower, J., 1978, Synthesis of Heat Exchanger Networks: I. Systematic Generation of Energy Optimal Networks, Alche, vol. 24, no. 4, pp. 633-642. https://doi.org/10.1002/aic. $\underline{690240411}$

[5] Klemeš, J., and Gundersen, T., 2013, Heat Integration: Targets and Heat, in Handbook of process integration (PI). Minimisation of Energy and Water use, Waste and Emmisions, Cambridge, Woodhead Publishing Limited, 1st ed, pp. 126-170. https://doi.org/10.1533/9780857097255

[6] Tewari,K., Agrawal, S., and Arya,R.,2015, Generalized Pinch Analysis Scheme Using MATLAB, Chemical Engineering and Technology, vol. 38, no. 3, pp. 530-536. https://doi.org/10.1002/ ceat. 201400475

\section{AUTHORS}

Kamel, D., is a lecturer in chemical engineering department with the British University of Egypt, Cairo, 11837 (e-mail: dina.ahmed@bue.edu.eg).

Gadalla, M.,. is associate professor in chemical engineering department with the British University of Egypt, Cairo, 11837 (e-mail: dina.ahmed@bue.edu.eg).

Ashour, F., is the head of chemical engineering department in Cairo University (e-mail: fhashour@yahoo.com).

Submitted 28 October 2016. Published as resubmitted by the authors 07 December 2016. 